\title{
Management of new symptoms of dyspepsia in the elderly in Quebec
}

Jacques LeLorier MD PhD FRCPC, Véronique Pagé MSc, Anne-Marie Castilloux MSc, Yvette LeLorier MSc

J LeLorier, V Pagé, A-M Castilloux, Y LeLorier. Management of new symptoms of dyspepsia in the elderly in Quebec. Can J Gastroenterol 1997;11(8):669-672.

OBJECTIVE: To use the Régie de l'assurance-maladie du Québec (RAMQ) database to study the clinical strategies used by Quebec physicians in the management of dyspepsia in the elderly.

DESIGN: A 20\% random sample of the RAMQ database for Quebec residents aged 65 years and older for the three years from July 1, 1991 to June 30, 1992 was used. Patients were placed in three cohorts according to the following treatment strategies: endoscopy, $x$-ray examination or drug therapy. Patients in each cohort were then categorized as either nonsteroidal anti-inflammatory drug (NSAID) users or non-NSAID users. The choice of drug treatment used to manage the dyspepsia in each cohort was recorded. Drug treatments were divided into the following six antidyspeptic categories: $\mathrm{H}_{2}$ blockers, omeprazole, sucralphate, misoprostol, prokinetic drugs or no drugs. The number of duodenal, oesophageal and stomach cancers diagnosed in each cohort was also counted.

RESULTS: Drug therapy was the most frequently used strategy in all patients, and was used more frequently in NSAID users (87\%) than in non-NSAID users (69\%). A total of $22 \%$ of NSAID users in each group, and $46 \%$ of NSAID users in the drug therapy group, underwent investigation. $\mathrm{H}_{2}$ blockers were the most prescribed drug in all three treatment strategies, and omeprazole was the second most prescribed drug in the endoscopy and $\mathrm{x}$-ray cohorts. Overall omeprazole was the least prescribed drug. There was a higher rate of cancer detection in the endoscopy and $\mathrm{x}$-ray cohorts than in the drug therapy group.

CONCLUSIONS: Previous NSAID use greatly influences the way in which physicians treat patients with dyspepsia.

Key Words: Dyspepsia, $\mathrm{H}_{2}$ blockers, Nonsteroidal anti-inflammatory drugs, Omeprazole, Régie de l'assurance-maladie du Québec (RAMQ) database

\section{Traitement des nouveaux symptômes de} dyspepsie chez la population âgée du Québec

OBJECTIF : Utiliser la base de données de la Régie de l'assurancemaladie du Québec pour étudier les stratégies cliniques utilisées par les médecins du Québec pour le traitement de la dyspepsie chez les gens âgés.

MODÈLE : Un échantillon aléatoire de $20 \%$ de la base de données de la RAMQ pour les résidents du Québec de 65 ans et plus pour les trois ans allant du $1^{\text {er }}$ juillet 1991 au 30 juin 1992 a été utilisé. Les patients ont alors été scindés en trois cohortes selon les stratégies thérapeutiques suivantes: endoscopie, examen radiologique ou traitement médicamenteux. Les patients de chaque cohorte ont été subdivisés selon qu'ils utilisaient ou non des anti-inflammatoires non stérö̈diens (AINS). Le choix du traitement médicamenteux utilisé pour traiter la dyspepsie dans chacune des cohortes a été consigné. Les traitements médicamenteux ont été divisés selon les six catégories d'antidyspeptiques suivants : anti- $\mathrm{H}_{2}$, oméprazole, sucralphate, misoprostol, procinétique ou aucun traitement médicamenteux. Le nombre de cancers du duodénum, de l'œsophage et de l'estomac diagnostiqués dans chacune des cohortes a également été calculé.

RÉSULTATS : Le traitement médicamenteux a été la stratégie la plus fréquemment utilisée chez tous les patients et a servi davantage chez les utilisateurs d'AINS ( $87 \%$ ) que chez les non-utilisateurs (69\%). En tout, $22 \%$ des utilisateurs d'AINS dans chacun des groupes et $46 \%$ des utilisateurs d'AINS dans le groupe traité au moyen de médicaments ont subi des épreuves diagnostiques. Les anti- $\mathrm{H}_{2}$ ont été le médicament le plus souvent prescrit dans les trois stratégies thérapeutiques et l'oméprazole est venu au deuxième rang des médicaments prescrits dans les cohortes ayant subi l'endoscopie et les examens radiologiques. De façon globale, l'oméprazole a été le médicament le moins prescrit. On a dépisté plus de cancers dans les cohortes soumises à l'endoscopie et à la radiologie que dans le groupe traité par médicament.

CONCLUSIONS : L'emploi antérieur d'AINS influe considérablement sur la façon dont les médecins traitent leurs patients souffrant de dyspepsie.

Centre de Recherche, Hôtel-Dieu de Montréal; and Department of Medicine and Pharmacology, University of Montreal, Montreal, Quebec Correspondence and reprints: Dr Jacques LeLorier, Research Center, CHUM, Pavillon Hôtel-Dieu, 3850 St-Urbain Street, Montreal, Quebec H2W 1T8. Telephone 514-843-2918, fax 514-843-2774, e-mail leloriej@ere.umontreal.ca

Received for publication June 26, 1997. Accepted September 17, 1997 
$\mathrm{D}$ yspepsia is a disease characterized by epigastric pain and discomfort. A simple clinical diagnosis of the disease is not always certain (1-8) because dyspepsia may be attributed to a large number of causal factors. An accurate diagnosis requires a diagnostic test, such as an endoscopy or upper gastrointestinal series. These tests, however, are expensive, and their availability is often limited by decreasing resources (9). A proposed alternative is to use the symptomatic response of patients to antisecretory (cimetidine, ranitidine, nizatidine), proton pump inhibitors (omeprazole) or mucosal protective agents (sucralphate, misoprostol) as first line therapy. Endoscopy and other such tests would then be reserved only for patients with refractory or relapsing symptoms. Only one randomized clinical trial has addressed the economic concerns surrounding this recommendation, and those authors concluded that using endoscopy first is a more cost effective strategy than using $\mathrm{H}_{2}$ blockers first (10).

We used the Régie de l'assurance-maladie du Québec (RAMQ) database to study the diagnostic and therapeutic approaches used by Quebec physicians to treat elderly patients with new symptoms of dyspepsia. We studied the effects of nonsteroidal anti-inflammatory drug (NSAID) use on the choice of strategy, and determined which therapeutic class of drugs was being prescribed most. Particular attention was paid to economic concerns regarding omeprazole, an effective yet expensive drug. Finally we analyzed the effects of clinical strategy on cancer detection.

\section{PATIENTS AND METHODS}

An observational study was performed using the RAMQ database. This database provides information on all the medical and pharmaceutical services received by Quebec residents aged 65 and older. A 20\% random file of the database for the three-year period from July 1, 1990 to June 30, 1993 was used.

Study population: The following three events were used as markers of potential dyspepsia: endoscopy; gastrointestinal radiological examination; or dispensation for one of the following type of drugs - antisecretory agents (cimetidine, famotidine, nizatidine and ranitidine), prokinetics (domperidone, cisapride, metoclopramide), mucosal protective agents (sucralphate or misoprostol) or omeprazole. Patients were eligible for the study if they had at least one of the three aforementioned events during the period from July 1, 1991 to June 30, 1992. The date of the first event was then identified as the index date for that patient. In order to identify new dyspepsia cases, only patients who were free from any of the above mentioned events one year before their index date were included in the study. Patients were then divided into the following three cohorts according to their index event: endoscopy, $\mathrm{x}$ ray or drug therapy.

NSAID use: Patients in each cohort were classified as either a NSAID user or a non-NSAID user. NSAID users were defined as patients having received at least one NSAID during the three months before their index date.

Drug therapy: In order to determine which antidyspeptic drugs were prescribed most by physicians, drugs were divided
TABLE 1

Demographic characteristics of each cohort

\begin{tabular}{|c|c|c|c|}
\hline & Endoscopy & X-ray & $\begin{array}{l}\text { Drug } \\
\text { therapy }\end{array}$ \\
\hline $\begin{array}{l}\text { Age (years) - median } \\
\quad \text { (first, third quartile) }\end{array}$ & $76(75,76)$ & $74(73,74)$ & $75(75,75)$ \\
\hline $\begin{array}{l}\text { Male (\%) } \\
\quad \text { (first, third quartile) }\end{array}$ & $46(44,49)$ & $34(31,37)$ & $35(34,36)$ \\
\hline $\begin{array}{c}\text { Number of days exposed } \\
\text { to other medication } \\
\text { (excluding NSAIDs) } \\
\text { - mean }(95 \% \mathrm{Cl})^{*}\end{array}$ & $\begin{array}{c}272 \\
(265-278)\end{array}$ & $\begin{array}{c}263 \\
(257-269)\end{array}$ & $\begin{array}{c}267 \\
(264-269)\end{array}$ \\
\hline $\begin{array}{c}\text { Number of dispensations } \\
\text { of other medications } \\
\text { (excluding NSAIDs) } \\
\text { - mean }(95 \% \mathrm{Cl})^{*}\end{array}$ & $43(40-46)$ & $32(30-34)$ & $37(36-38)$ \\
\hline $\begin{array}{l}\text { Number of days exposed } \\
\text { to NSAIDs - mean } \\
(95 \% \mathrm{Cl})^{\star}\end{array}$ & $40(35-44)$ & $34(30-38)$ & $45(43-47)$ \\
\hline $\begin{array}{l}\text { Number of NSAID } \\
\text { dispensations - mean } \\
(95 \% \mathrm{Cl})^{\star}\end{array}$ & $2(1-2)$ & $1(1-1)$ & $2(2-2)$ \\
\hline $\begin{array}{l}\text { Number of medical visits } \\
- \text { mean }(95 \% \mathrm{Cl})^{*}\end{array}$ & $32(30-33)$ & $19(18-20)$ & $22(21-23)$ \\
\hline $\begin{array}{l}\text { Number of days in hospital } \\
- \text { mean }(95 \% \mathrm{Cl})^{\star}\end{array}$ & $22(20-23)$ & $6(6-7)$ & $12(12-13)$ \\
\hline
\end{tabular}

${ }^{*}$ Determined one year before the index date. NSAID Nonsteroidal antiinflammatory drug

TABLE 2

Clinical strategy chosen for elderly patients with new symptoms of dyspepsia

\begin{tabular}{lcccc}
\hline & Endoscopy & X-ray & Drug therapy & Total \\
\hline NSAID & 284 & 273 & 3633 & 4190 \\
$\quad$ users & $(6.8 \%)$ & $(6.5 \%)$ & $(86.7 \%)$ & $(100 \%)$ \\
Non-NSAID & 957 & 968 & 4293 & 6218 \\
$\quad$ users & $(15.4 \%)$ & $(15.6 \%)$ & $(69.0 \%)$ & $(100 \%)$ \\
Total & 1241 & 1241 & 7926 & 10,408 \\
& & & & $(100 \%)$ \\
\hline
\end{tabular}

NSAID Nonsteroidal anti-inflammatory drug

into six categories: $\mathrm{H}_{2}$ blockers, omeprazole, sucralphate, misoprostol, prokinetic drugs or no drugs. The number and percentage of patients in each category were determined in each of the three cohorts. For the patients in the endoscopy and $\mathrm{x}$-ray cohort, the first dispensation that occurred within 30 days after the index event was determined. For those in the drug therapy cohort, only the drug prescribed on the index date was counted.

Cancer study: Patients were placed in the diagnostic test cohort if their index event was an endoscopy or $\mathrm{x}$-ray examination. Patients who received drug therapy as their index event were placed in the drug therapy cohort. The number of duodenal, oesophageal and stomach cancers that were diagnosed up to one year after the index date were determined in each group.

Statistical analysis: All statistical analyses were carried out with the SAS statistical package (SAS Institute, North 
TABLE 3

First drug dispensed to patients in each of the three cohorts

\begin{tabular}{lcccc}
\hline & Endoscopy* & X-ray $^{*}$ & $\begin{array}{c}\text { Drug } \\
\text { therapy }\end{array}$ & Overall \\
\hline $\mathrm{H}_{2}$ blockers & 269 & 198 & 3650 & 4117 \\
& $(21.7 \%)$ & $(16.0 \%)$ & $(46.1 \%)$ & $(39.6 \%)$ \\
Omeprazole & $133(10.7 \%)$ & $46(3.7 \%)$ & $475(6.0 \%)$ & $654(6.3 \%)$ \\
Sucralphate & $52(4.2 \%)$ & $17(1.4 \%)$ & 1012 & 1081 \\
& & & $(12.7 \%)$ & $(10.4 \%)$ \\
Misoprostol & $11(0.9 \%)$ & $3(0.2 \%)$ & 1426 & 1440 \\
& & & $(18.0 \%)$ & $(13.8 \%)$ \\
Motility & $47(3.8 \%)$ & $41(3.3 \%)$ & 1363 & 1451 \\
$\quad$ drugs & & & $(17.2 \%)$ & $(13.9 \%)$ \\
No drug & $729(58.7 \%)$ & 936 & 0 & 1665 \\
& & $(75.4 \%)$ & & $(16.0 \%)$ \\
Total & 1241 & 1241 & 7926 & 10,408 \\
\hline
\end{tabular}

${ }^{*}$ For patients in the endoscopy and $x$-ray cohorts only, the first drug prescribed within 30 days of the index event was considered

Carolina). Results are presented as a percentage; a mean with corresponding $95 \%$ CIs; or as a median with corresponding first and third quartiles.

\section{RESULTS}

The main demographic characteristics of the three cohorts at the time of the index event are displayed in Table 1. The endoscopy cohort differed from the other two cohorts in several respects. In this cohort, there was a greater percentage of men, more dispensations of other medications, more medical visits and more days in the hospital than in the other two cohorts. In terms of the effects of NSAID use on the choice of clinical strategy (Table 2), drug therapy was the most frequently used strategy in all patients, and was used more frequently in NSAID users (87\%) than in non-NSAID users (69\%). NSAID users are more often treated with misoprostol $(36.1 \%)$ compared with non-NSAID users $(2.7 \%)$. It was also found that the percentage of NSAID users $(22 \%)$ was similar among patients who received endoscopies or $\mathrm{x}$-rays.

Drug frequency analysis showed that, overall, $\mathrm{H}_{2}$ blockers were the drug of choice in all three cohorts (Table 3). Omeprazole was the second most prescribed drug in the endoscopy cohort. However, when the overall number of drug prescriptions in all three cohorts was considered, omeprazole was the least prescribed drug. No antidyspeptic drugs were prescribed (up to 30 days after a diagnostic test) in $75.4 \%$ of patients in the $\mathrm{x}$-ray cohort and in $58.7 \%$ of the endoscopy cohort (Table 3). When the observation period was extended to one year after the diagnostic test, $56.6 \%$ of the $\mathrm{x}$ ray cohort and $45.9 \%$ of the endoscopy cohort remained free from antidyspeptic drugs.

The relatively large amount of time that elapsed between the prescription of the drug and its dispensation in the patients subjected to an endoscopy indicates that these patients had relatively mild symptoms (Table 4). One can also conclude that omeprazole, the most effective drug, was not selectively prescribed to patients with the most severe symp-
TABLE 4

Days elapsed between endoscopy and first drug dispensation up to $\mathbf{3 0}$ days after the endoscopy

\begin{tabular}{llc}
\hline Drug & Mean $(95 \% \mathrm{Cl})$ & Median (first, third quartile) \\
\hline $\mathrm{H}_{2}$ blockers & $7.06(6.21-7.91)$ & $5(1,11)$ \\
Motility drugs & $4.26(2.80-5.71)$ & $3(0,7)$ \\
Omeprazole & $5.95(4.68-7.24)$ & $3(0,8)$ \\
Sucralphate & $5.44(3.64-7.24)$ & $4(0,8)$ \\
Misoprostol & $9.55(4.36-14.73)$ & $4(2,19)$ \\
All drugs & $6.40(5.78-7.02)$ & $4(1,9)$ \\
\hline
\end{tabular}

TABLE 5

Cancers diagnosed during the year following the index event

\begin{tabular}{lccc}
\hline & Diagnostic test & Drug & Total \\
\hline $\mathrm{N}$ & 5704 & 1391 & 7095 \\
All cancers & $43(0.75 \%)$ & $3(0.22 \%)$ & $46(0.65 \%)$ \\
Stomach & $30(0.53 \%)$ & $3(0.22 \%)$ & $33(0.47 \%)$ \\
Esophagus & $13(0.23 \%)$ & $0(0.0 \%)$ & $13(0.18 \%)$ \\
\hline
\end{tabular}

$P=0.025$ (all cancers, test first versus drug first)

toms because these patients were not more prompt in having their prescriptions filled (median of 5.95 days) compared with patients on other drug therapies. One would expect a patient with severe symptomology to have the prescription filled by the pharmacist soon after it was written by the physician.

In the year following the index event, the number of patients with cancer (Table 5) was higher in the diagnostic test group $(0.75 \%)$ than in the drug therapy group $(0.22 \%)$.

\section{DISCUSSION}

The management of dyspepsia in the elderly poses several challenging problems that are compounded by the high prevalence and vague nature of the symptoms. A physician facing an elderly patient complaining of new symptoms of dyspepsia has essentially three options: watchful waiting; prescription of a drug; or a diagnostic test. While in some circumstances the right course might be obvious, in most cases the medical literature provides little evidence on which to establish the proper strategy. It is thus of interest to use an observational tool such as the RAMQ database to attempt to describe physician behaviour and some of its consequences.

We can conclude from our study that NSAID and nonNSAID users are approached differently. NSAID users have fewer diagnostic tests (Table 2). Because NSAIDs are a known contributing factor in dyspepsia, physicians may be attributing the dyspepsia to the use of NSAIDs, thereby decreasing any need for diagnostic tests. Similarly, NSAID users were placed on misoprostol more often than other patients because misoprostol is the only drug officially approved in Canada for the treatment of NSAID-induced gastropathy. That there was an equal number of endoscopies and radiological examinations in both NSAID and nonNSAID users probably indicates that the choice between 
these two strategies is more dependent on availability and physician preferences than on clinical characteristics of individual patients.

Interestingly, $45.9 \%$ of the endoscopy patients and $56.6 \%$ of the $\mathrm{x}$-ray patients did not receive any antidyspepsic drug during the year following the test. This finding may result from patients subsequently being less likely to consume drugs or seek further medical services once receiving a negative diagnostic test result.

According to our data, omeprazole does not appear to be overused (Table 3). The higher number of patients being put on omeprazole after endoscopy $(10.7 \%)$ does not appear to be inappropriate because these patients are probably more symptomatic or discovered upon investigation to have more severe disease.

Our study indicates that $0.65 \%$ of the patients older than 65 years who are treated by a physician for new symptoms of dyspepsia had an upper gastrointestinal cancer diagnosed in the year following the index event. Although patients in the diagnostic test cohort had a higher cancer diagnosis rate $(0.75 \%)$ than those in the drug therapy cohort $(0.22 \%)$, this does not necessarily mean that patients in the diagnostic test cohort are better off. A likely explanation is that the sicker patients (those with alarming concomitant symptoms like weight loss or difficulty swallowing) were preferentially assigned to a diagnostic test. It is therefore not surprising that more cancers were found in this group. However, because of the lead time bias, an early diagnosis of cancer only represents an advantage to the patient if it improves the chances of survival. Otherwise, the patient spends more time knowing he or she has cancer but does not necessarily live longer. On the other hand, there is a potential delay in the diagnosis of upper gastrointestinal cancer in patients who are initially treated medically and only investigated if they do not respond to medical therapy or if they develop alarming symptoms. It is, however, possible that in some cases such delay might have detrimental effects on their prognosis.

It will be of interest to study the evolution of these behaviour patterns over time to observe the impact of new infor-

\section{REFERENCES}

1. Davenport P, Morgan A, Darnborough A, De Dombal F. Can preliminary screening of dyspeptic patients allow more effective use of investigational techniques? BMJ 1985;290:217-20.

2. Johannessen T, Petersen $\mathrm{H}$, Kleveland $\mathrm{P}$, et al. The predictive value of history in dyspepsia. Scand J Gastroenterol 1990;25:689-97.

3. Bytzer P, Schaffalitzky de Muckadell O. Prediction of major pathologic conditions in dyspeptic patients referred for endoscopy: a prospective validation study of a scoring system. Scand J Gastroenterol 1992;27:987-92.

4. Edenholm M, Gustavsson R, Jansson O, et al. Endoscopic findings in patients with ulcer-like dyspepsia. Scand J Gastroenterol 1985;20(Suppl 109):163-7.

5. Bhattacharya I. Evaluation and management of dyspepsia. Hosp Pract 1992;27:93-101.

6. Talley N, McNeil D, Piper D. Discriminant value of dyspeptic symptoms. Gut 1987;28:40-6. mation, such as the advantages of Helicobacter pylori eradication, and of recent regulatory decisions, including over-the-counter sale of $\mathrm{H}_{2}$ blockers.

Study limitations: This study was done on the RAMQ database whose primary purpose is to administer and control physician and pharmacist claims. The RAMQ database has been proven to be accurate within $3.1 \%$ for prescription claims (11). It is an excellent tool to capture exposure to drugs. However, the information provided by the database relates only to dispensations; therefore it must be assumed that dispensed drugs are actually consumed by patients. Furthermore, the RAMQ database does not record over-the-counter medications or prescription written by physicians but never filled.

The diagnosis included in a regular physician visit undoubtedly constitutes the weakest part of the RAMQ (and most administrative databases) because only one diagnosis is required to process a medical claim. Patients suffering from several conditions (such as the elderly) are therefore only registered under one of their medical conditions. The result is that information regarding all other conditions or diseases are absent.

Another limitation of the database is that very important clinical information, such as intensity of symptoms, weight loss, and smoking and drinking habits, is not available.

In addition, database studies, like all observational studies, may be subject to indication bias in which patients with specific clinical characteristics are chosen for certain diagnostic or therapeutic strategies that might influence their outcome. For instance, sicker patients may preferentially be given a diagnostic test or a specific drug that is perceived as being more effective; as a result, these sicker patients are expected to have poorer outcomes. Indication bias is the main reason why statements on cause-effect relationships have to be avoided or made with great reservations when based on administrative databases. Despite these limitations, administrative databases are invaluable tools to observe, in a naturalistic setting, patients and physician behaviour, as well as patterns of drug use and diagnostic tests.

7. Johnsen R, Bernersen B, Straume B, Forde O, Burhol P. Prevalences of endoscopy and histological findings in subjects with and without dyspepsia. BMJ 1991;302:749-52.

8. Cann P, Gleeson M, Robinson T, Wicks A. Assessing dyspepsia in general practice. Br J Med Pract 1994;48:263-7.

9. Williams B, Luckas M, Ellingham J, Dain A, Wicks A. Do young patients with dyspepsia need investigation? Lancet 1988;ii:1349-51.

10. Bytzer P, Hansen J, Schaffallitzky de Muckadell O. Empirical $\mathrm{H}_{2}$-blocker therapy of prompt endoscopy in management of dyspepsia. Lancet 1994;343:811-6.

11. Tamblyn R, Lavoie G, Petrella L, Monette J. The use of prescription claims databases in pharmacoepidemiology research: the accuracy and comprehensiveness of the prescription claims database in Quebec. J Clin Epidemiol 1995;48:999-1009. 


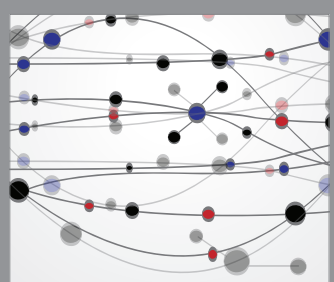

The Scientific World Journal
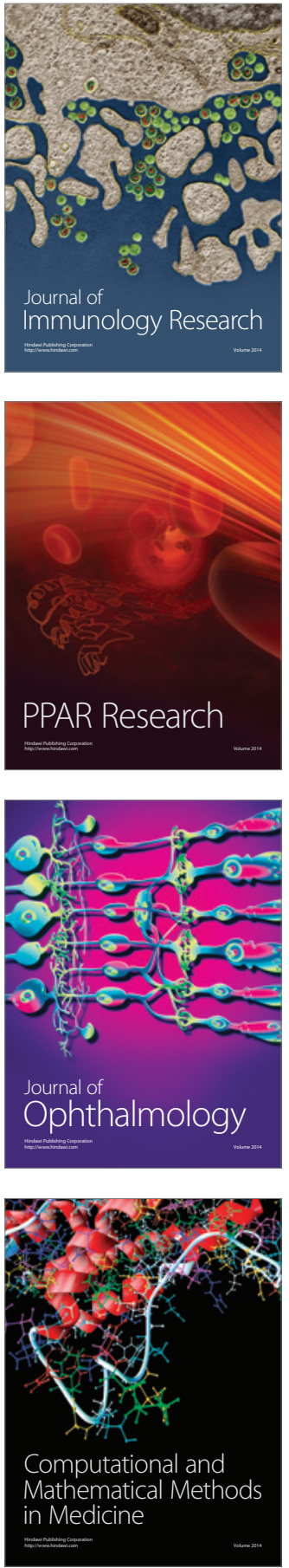

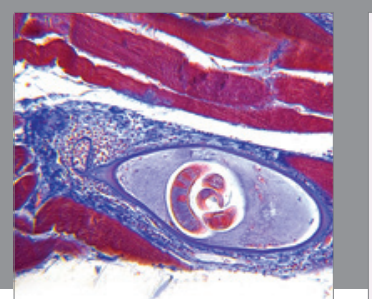

Gastroenterology Research and Practice

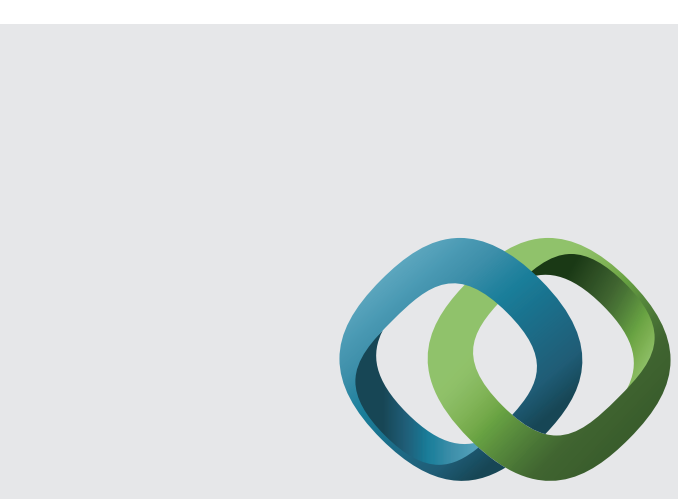

\section{Hindawi}

Submit your manuscripts at

http://www.hindawi.com
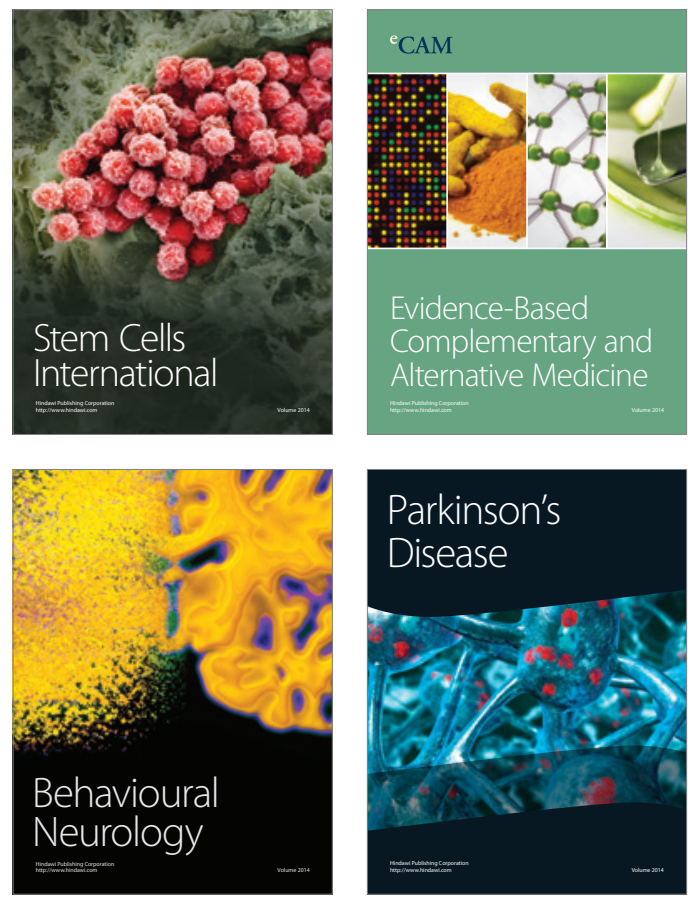
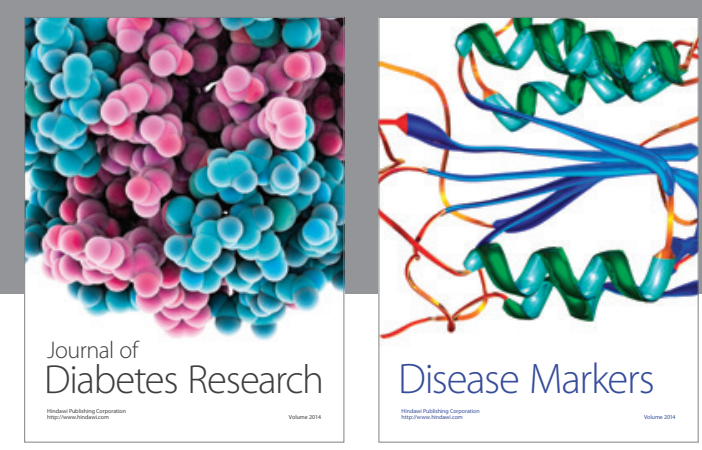

Disease Markers
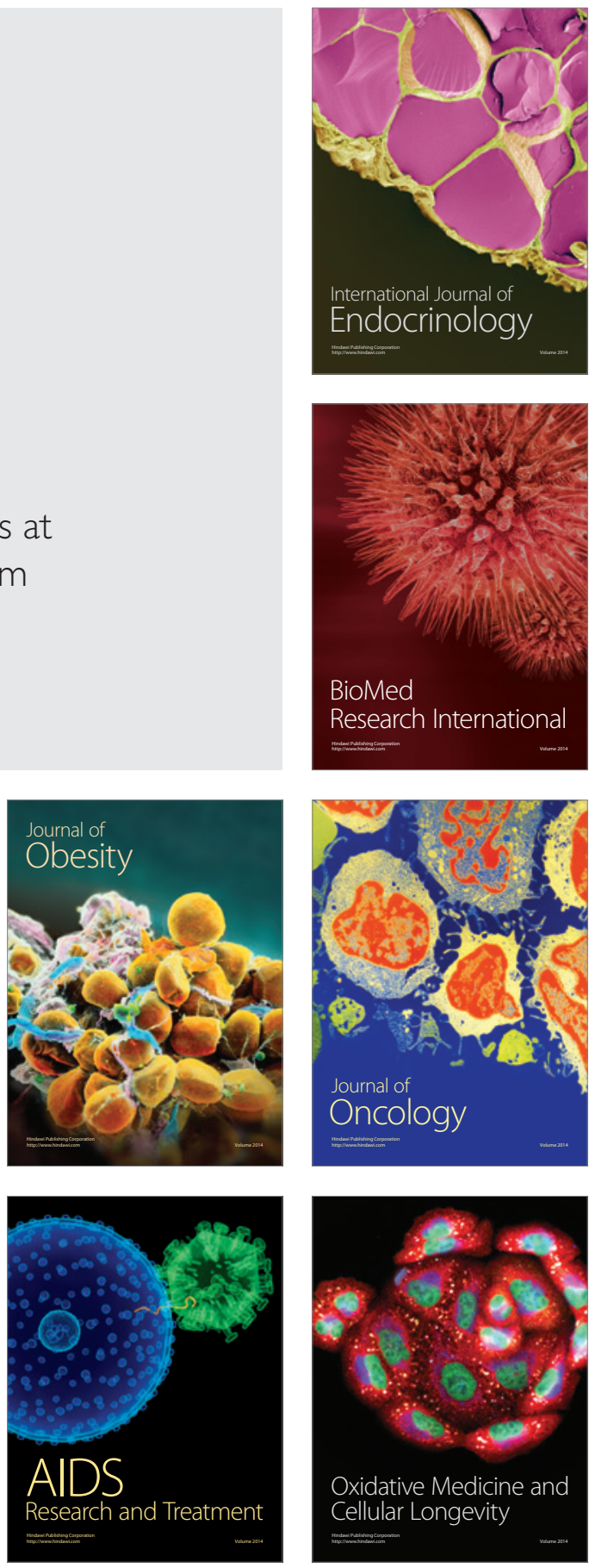